Article

\title{
Interpretation of Forest Resources at the Individual Tree Level at Purple Mountain, Nanjing City, China, Using WorldView-2 Imagery by Combining GPS, RS and GIS Technologies
}

\author{
Songqiu Deng ${ }^{1,2, *}$, Masato Katoh ${ }^{1}$, Qingwei Guan ${ }^{2}, \mathrm{Na} \mathrm{Yin}^{3}$ and Mingyang $\mathrm{Li}^{2}$
}

1 Forest Measurement and Planning Laboratory, Agriculture Faculty, Shinshu University, 8304, Minamiminowa-Vill., Kamiina-Dtrct., Nagano 399-4598, Japan; E-Mail: mkatoh@shinshu-u.ac.jp

2 Forest Resources and Environment Faculty, Nanjing Forestry University, Nanjing 210037, China; E-Mails: guanjapan999@163.com (Q.G.); 1my196727@126.com (M.L.)

3 Forest Environment and Ecology Laboratory, Agriculture Faculty, Shinshu University, 8304, Minamiminowa-Vill., Kamiina-Dtrct., Nagano 399-4598, Japan; E-Mail: yinna2012@yahoo.co.jp

* Author to whom correspondence should be addressed; E-Mail: deng0316@yahoo.com; Tel.: +81-265-77-1642; Fax: +81-265-77-1642.

Received: 22 October 2013; in revised form: 2 December 2013 / Accepted: 10 December 2013 / Published: 20 December 2013

\begin{abstract}
This study attempted to measure forest resources at the individual tree level using high-resolution images by combining GPS, RS, and Geographic Information System (GIS) technologies. The images were acquired by the WorldView-2 satellite with a resolution of $0.5 \mathrm{~m}$ in the panchromatic band and $2.0 \mathrm{~m}$ in the multispectral bands. Field data of 90 plots were used to verify the interpreted accuracy. The tops of trees in three groups, namely $\geq 10 \mathrm{~cm}, \geq 15 \mathrm{~cm}$, and $\geq 20 \mathrm{~cm} \mathrm{DBH}$ (diameter at breast height), were extracted by the individual tree crown (ITC) approach using filters with moving windows of $3 \times 3$ pixels, $5 \times 5$ pixels and $7 \times 7$ pixels, respectively. In the study area, there were $1,203,970$ trees of DBH over $10 \mathrm{~cm}$, and the interpreted accuracy was $73.68 \pm 15.14 \%$ averaged over the 90 plots. The numbers of the trees that were $\geq 15 \mathrm{~cm}$ and $\geq 20 \mathrm{~cm}$ DBH were 727,887 and 548,919, with an average accuracy of $68.74 \pm 17.21 \%$ and $71.92 \pm 18.03 \%$, respectively. The pixel-based classification showed that the classified accuracies of the 16 classes obtained using the eight multispectral bands were higher than those obtained using only the four standard bands. The increments ranged from $0.1 \%$ for the water class to $17.0 \%$ for Metasequoia glyptostroboides, with an average value of $4.8 \%$ for the 16 classes. In addition, to overcome the "mixed pixels" problem, a crown-based supervised classification, which can improve the classified accuracy of both dominant
\end{abstract}


species and smaller classes, was used for generating a thematic map of tree species. The improvements of the crown- to pixel-based classification ranged from $-1.6 \%$ for the open forest class to $34.3 \%$ for Metasequoia glyptostroboides, with an average value of $20.3 \%$ for the 10 classes. All tree tops were then annotated with the species attributes from the map, and a tree count of different species indicated that the forest of Purple Mountain is mainly dominated by Quercus acutissima, Liquidambar formosana and Pinus massoniana. The findings from this study lead to the recommendation of using the crown-based instead of the pixel-based classification approach in classifying mixed forests.

Keywords: 3S technology; forest resource measurement; individual tree crown approach; object-based classification; Purple Mountain

\section{Introduction}

Forest resource information, such as species composition, stem density and $\mathrm{DBH}$, is the basis of sustainable forest management. Traditional field surveys for forest resource management include the number of trees, species and measurements of DBH and tree height in small sample plots. Three to five plots are usually established in each compartment (the minimum unit of forest management). The structure of the entire forest resource is estimated by multiplying these measured values by the total forest area. However, this method is less accurate for large forests in which stand conditions, species and stem densities vary [1]. It is nearly impossible to obtain spatially-explicit stand information on tree species composition and distribution patterns over large areas purely on the basis of field assessments [2]. However, because the forests of China are vast, with a total area of approximately 195.45 million hectares in 2008 [3], conducting national forest inventories by the sample plot method every five years is too costly and time-consuming. Therefore, the acquisition of spatially detailed forest information over large areas by other enhanced methods has become an urgent topic of study [4,5].

This task has been enabled by the advent of remote sensing techniques, which can obtain various types of spatial information simultaneously, such as the coverage type of the ground surface, position, and DEM data. The launch of the LANDSAT satellite in 1972 enabled the study of forests at a global scale. For tree species classification at the crown scale in forests with high species diversity, data with both high spatial and spectral resolution that can identify objects of small sizes, such as cars and tree crowns, are required [6-8]. Since the 1990s, airborne digital sensors with four multispectral bands and very high spatial resolution have been applied successfully for forest studies in developed countries, such as the USA, Canada, Germany and Japan [9-12]. However, due to their wide field of view, aerial photos are subject to strong effects caused by the bi-directional reflectance characteristics of most land cover types [2]. Depending on the sun-view-geometry, which varies with the position of the object within the image, the spectral signature of an object can differ significantly [2]. Although these effects can be useful in special image analysis techniques [13], they are usually regarded as a limiting factor in the automated analysis of aerial images. Due to high costs and their limited availability, airborne data have gained only limited acceptance for operational use. 
Commercial satellites, including IKONOS, QuickBird, GeoEye-1 and WorldView-2, were launched successfully in 1999, 2001, 2008 and 2009, respectively. These satellites can obtain imagery at low cost for several areas simultaneously with a very high resolution of $1 \mathrm{~m}$ or less in panchromatic mode, enabling the measurement of forest resources at the individual tree level by satellite remote sensing and computer technology [14-16]. In recent years, the damaged ecological environment of China has required forest conservation instead of wood harvest. For the purpose of forest protection, many forest parks and nature reserves have been established in China, and most of them have been transformed from state-owned forest farms whose goal of operation in the past was the production of wood. However, because of little management, there were many problems in these young man-made forests, such as low species richness and diversity, simple structure and poor growth because of high density. The management of these areas requires spatially detailed information concerning the forest on a large scale. In addition, in modern forest management, the selective thinning approach was used to replace the traditional clear-cutting of trees. Accurate forest information at the individual tree level is of high importance for the selection of target trees. Therefore, individual tree crown delineation methods have received greater attention from researchers in the forest remote sensing field [17-20].

Several algorithms can automate tree crown delineation. Extraction methods for delineating tree crowns include three main approaches: bottom-up, top-down and template matching algorithms. The valley-following method is a bottom-up algorithm. Top-down algorithms can be divided into watershed, multiple-scale edge segments, threshold-based spatial clustering and double-aspect methods. The template-matching algorithms match a synthetic image model or template of a tree crown to radiometric values [21-23]. The valley-following method, developed by Gougeon [24], has been successfully used to extract tree crowns and tops of man-made coniferous forests in temperate zones by using aerial photographs [18-20]. Additionally, the individual tree crown (ITC) approach using the valley-following method has been successfully programmed by the Pacific Forestry Centre of the Canadian Forest Service, which made it possible to delineate tree crowns and tops on a large scale. This approach can be used to gather detailed crown information at the stand level over a large area for forest inventories [14]. However, the usefulness of this method for various types of vegetation remains to be verified. In addition, few studies of the semi-automatic extraction of tree tops, the delineation of tree crowns, and tree quantifications of forests using satellite images with high resolution have been reported $[2,25]$.

The WorldView-2, a new satellite-borne sensor, was launched by DigitalGlobe in 2009. Its very high spatial resolution $(0.5 \mathrm{~m}$ in the panchromatic band and $2.0 \mathrm{~m}$ in multispectral bands) and four new multispectral bands (Coastal, Yellow, Red-Edge and NIR2) in addition to the four standard bands (Blue, Green, Red and NIR1) were expected to have high potential for forest studies, because the satellite provides more abundant multispectral information compared to traditional optical sensors [2,26,27]. In this study, using WorldView-2 data, we attempt to first quantify the forest resources of the Purple Mountain in Nanjing at the tree level by applying the ITC approach, a semi-automatic approach of tree crown delineation with a valley-following algorithm, and tree top extraction with a local maxima filtering technique [28]. We also hope to clarify the validity of this method for various forest types with complicated spatial structures in the transitional zone between subtropical and warm-temperate forests. Therefore, the entire mountain, which is mainly composed of man-made single forests, secondary deciduous forest and coniferous-broadleaved mixed forest dominated by Pinus massoniana, 
Liquidambar formosana and Quercus acutissima, was the object of interest in this study. Finally, we focus on the question of whether the four additional bands of WorldView-2 can improve the classification accuracy significantly compared to the four standard bands.

\section{Materials and Methods}

\subsection{Study Area}

The study area, Purple Mountain National Park $\left(32^{\circ} 01^{\prime}-32^{\circ} 06^{\prime}\right.$ N, $118^{\circ} 48^{\prime}-118^{\circ} 53^{\prime}$ E), has an area of approximately 4,500 ha and is situated in the center of Nanjing City, southeastern Jiangsu Province, China (Figure 1). The altitudes above sea level at the top and foot of the mountain are approximately $449 \mathrm{~m}$ and $20 \mathrm{~m}$, respectively. The annual average precipitation is $1,000 \mathrm{~mm}$ to $1,050 \mathrm{~mm}$, and the average sunshine hours are approximately $2,213 \mathrm{~h}$ per year. The annual mean temperature is $15.4{ }^{\circ} \mathrm{C}$, with a high temperature of $40.7{ }^{\circ} \mathrm{C}$ in August and a low temperature of $-14.0{ }^{\circ} \mathrm{C}$ in January [29]. The zonal soil color is yellow brown [30], with purple forest soil found on the northern mountain with a steep slope [29].

The zonal vegetation type in Nanjing is deciduous broad-leaved mixed forest with some evergreen trees. However, because of long-term wars and human disturbances, all of the natural forest in Purple Mountain has been damaged, with the exception of some areas around Linggu Temple and Ming Xiaoling Mausoleum. Since the 1930s, more attention has been paid to afforestation in the study area. The mountain was covered completely by manmade forest until the 1960s. In the late 1970s, many coniferous trees died from pine wilt disease. Many broad-leaved trees, such as Quercus acutissima and Pistacia chinensis, invaded the gaps successfully and had good growth. At the same time, the surviving zonal vegetation recovered favorably, because cutting was forbidden. Today, the forest of Purple Mountain is mainly composed of manmade single forest approximately 60 to 80 years of age, as well as secondary deciduous forest and coniferous - broadleaved mixed forest dominated by Pinus massoniana, Quercus fabri, Liquidambar formosana and Quercus acutissima [31].

\subsection{Field Measurements}

In this study, we selected the entire mountain, with an area of approximately $30 \mathrm{~km}^{2}$, as the research object. A total of 90 plots with sizes of $15 \times 15 \mathrm{~m}, 20 \times 20 \mathrm{~m}$ or $25 \times 25 \mathrm{~m}$ were established in September 2011, for testing the accuracy of the interpretation of the tree tops and the supervised classification of tree species (Figure 1). In the heterogeneous areas, the plots had a large size for improving the representativeness, whereas the plots of homogeneous forests were set with small sizes. These plots were chosen on the basis of forest conditions, various terrains and accessibility for measurement and were distributed in different forest types. The number of the $15 \times 15 \mathrm{~m}, 20 \times 20 \mathrm{~m}$ and $25 \times 25$ m plots was 33,49 and 8 , respectively.

All trees with a DBH larger than $5 \mathrm{~cm}$ were surveyed, as well as their species, DBH and height. Each tree was tagged with a label and noted as either live or dead. In addition, the center of each plot was measured by GPS (Garmin MAP 60CS; accuracy: $\pm 3 \mathrm{~m}$ ). All central points of the 90 plots were recorded when the GPS steadily displayed the highest accuracy of $\pm 3 \mathrm{~m}$. The average $\mathrm{DBH}$, tree height and stem density in each plot were calculated, and the plots were divided into three stand types: 
broad-leaved (B in Table 1), coniferous (C) and mixed (M) forest. Finally, we verified the correspondence of the observed and estimated tree densities in the central point of each plot and calculated the accuracy of the interpretation of the tree tops. The conditions of the 90 plots are documented in Table 1.

Figure 1. Location map of the study area with vegetation types in 2002 and the plot positions investigated in September, 2011. The location map was cited from Google Earth, and the vegetation map was from the ArcGIS (GIS, Geographic Information System) database established in 2002.

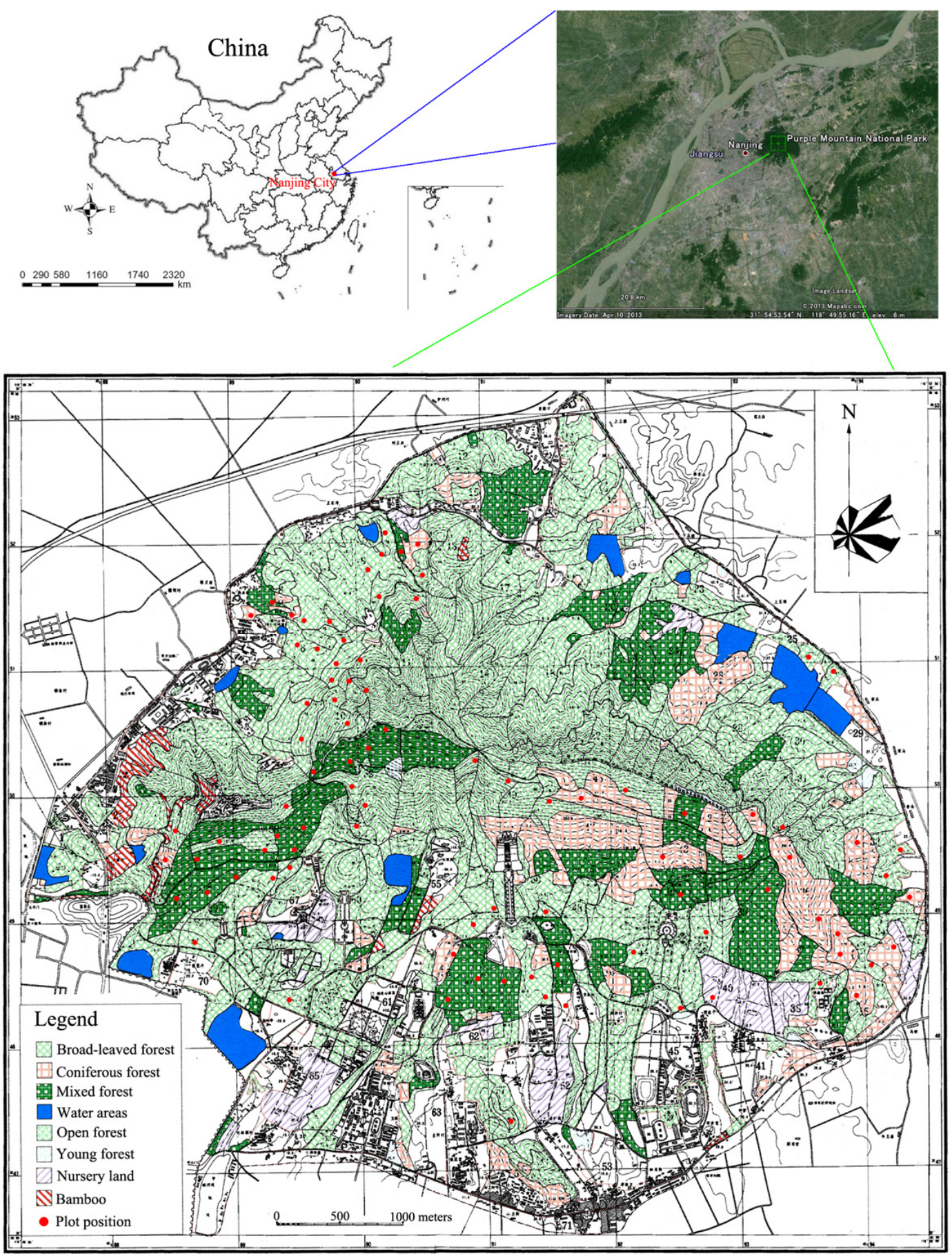


Table 1. The condition of the 90 plots surveyed in September, 2011. DBH, diameter at breast height. B, broad-leaved; M, mixed; C, coniferous.

\begin{tabular}{|c|c|c|c|c|c|c|c|c|c|}
\hline No. & $\begin{array}{c}\text { Density } \\
\text { (Stem/ha) }\end{array}$ & $\begin{array}{c}\text { Average } \\
\text { DBH }(\mathbf{c m})\end{array}$ & $\begin{array}{c}\text { Average } \\
\text { Height (m) }\end{array}$ & $\begin{array}{c}\text { Forest } \\
\text { Type }\end{array}$ & NO. & $\begin{array}{c}\text { Density } \\
\text { (Stem/ha) }\end{array}$ & $\begin{array}{c}\text { Average } \\
\text { DBH }(\mathbf{c m})\end{array}$ & $\begin{array}{c}\text { Average } \\
\text { Height (m) }\end{array}$ & $\begin{array}{c}\text { Forest } \\
\text { Type }\end{array}$ \\
\hline 1 & 311 & 36.2 & 12.0 & $\mathrm{~B}$ & 46 & 2,000 & 11.9 & 8.8 & $\mathrm{M}$ \\
\hline 2 & 1,956 & 10.1 & 8.6 & B & 47 & 1,422 & 12.9 & 9.6 & M \\
\hline 3 & 1,467 & 13.0 & 10.0 & M & 48 & 711 & 18.0 & 11.0 & $\mathrm{~B}$ \\
\hline 4 & 1,289 & 12.4 & 9.5 & $\mathrm{C}$ & 49 & 1,022 & 12.5 & 9.4 & M \\
\hline 5 & 1,378 & 16.2 & 10.8 & $\mathrm{C}$ & 50 & 2,178 & 11.2 & 8.8 & $\mathrm{M}$ \\
\hline 6 & 844 & 16.6 & 11.2 & B & 51 & 2,178 & 10.1 & 8.4 & M \\
\hline 7 & 1,644 & 12.2 & 9.4 & $\mathrm{M}$ & 52 & 1,378 & 12.6 & 9.4 & $\mathrm{M}$ \\
\hline 8 & 1,956 & 12.7 & 9.5 & M & 53 & 1,422 & 15.4 & 10.4 & M \\
\hline 9 & 1,100 & 17.2 & 11.4 & $\mathrm{M}$ & 54 & 1,778 & 12.1 & 9.2 & $\mathrm{M}$ \\
\hline 10 & 1,156 & 16.5 & 11.1 & M & 55 & 1,067 & 13.6 & 10.1 & M \\
\hline 11 & 1,375 & 14.0 & 10.0 & $\mathrm{M}$ & 56 & 1,111 & 15.3 & 11.0 & $\mathrm{C}$ \\
\hline 12 & 1,244 & 13.2 & 9.4 & $\mathrm{C}$ & 57 & 1,200 & 11.0 & 8.9 & B \\
\hline 13 & 2,075 & 10.7 & 8.4 & $\mathrm{C}$ & 58 & 1,156 & 14.8 & 10.3 & B \\
\hline 14 & 1,822 & 11.6 & 8.9 & M & 59 & 1,689 & 11.9 & 9.7 & B \\
\hline 15 & 844 & 17.8 & 11.3 & B & 60 & 1,911 & 10.8 & 8.6 & M \\
\hline 16 & 1,644 & 11.9 & 8.6 & M & 61 & 1,067 & 10.0 & 8.0 & M \\
\hline 17 & 1,650 & 13.6 & 10.4 & $\mathrm{~B}$ & 62 & 1,467 & 10.6 & 8.7 & $\mathrm{~B}$ \\
\hline 18 & 650 & 15.7 & 11.1 & $\mathrm{M}$ & 63 & 1,111 & 14.6 & 10.4 & B \\
\hline 19 & 1,333 & 13.0 & 9.2 & $\mathrm{M}$ & 64 & 1,644 & 13.5 & 9.8 & $\mathrm{C}$ \\
\hline 20 & 1,125 & 13.4 & 9.3 & B & 65 & 1,175 & 11.5 & 8.6 & B \\
\hline 21 & 1,400 & 10.2 & 7.9 & B & 66 & 1,250 & 13.2 & 9.5 & B \\
\hline 22 & 1,325 & 15.4 & 10.3 & B & 67 & 533 & 11.3 & 9.0 & B \\
\hline 23 & 1,156 & 13.5 & 9.6 & B & 68 & 533 & 17.5 & 11.1 & B \\
\hline 24 & 978 & 19.4 & 12.4 & B & 69 & 889 & 9.9 & 8.4 & B \\
\hline 25 & 1,289 & 12.2 & 9.2 & B & 70 & 1,556 & 10.0 & 8.2 & M \\
\hline 26 & 800 & 16.1 & 10.3 & $\mathrm{M}$ & 71 & 1,111 & 11.4 & 8.6 & $\mathrm{~B}$ \\
\hline 27 & 1,689 & 10.8 & 8.7 & B & 72 & 1,778 & 10.2 & 8.3 & B \\
\hline 28 & 1,689 & 10.3 & 8.9 & $\mathrm{M}$ & 73 & 1,378 & 15.2 & 9.9 & B \\
\hline 29 & 1,378 & 11.9 & 9.3 & B & 74 & 933 & 17.7 & 10.9 & B \\
\hline 30 & 1,467 & 12.2 & 9.2 & B & 75 & 1,956 & 10.1 & 8.4 & B \\
\hline 31 & 1,422 & 15.5 & 10.8 & $\mathrm{M}$ & 76 & 1,911 & 10.6 & 8.7 & B \\
\hline 32 & 1,467 & 15.9 & 10.8 & $\mathrm{M}$ & 77 & 1,289 & 13.8 & 10.4 & B \\
\hline 33 & 550 & 27.9 & 14.4 & $\mathrm{M}$ & 78 & 1,467 & 13.5 & 10.1 & B \\
\hline 34 & 1,067 & 16.6 & 10.0 & B & 79 & 2,000 & 11.6 & 9.4 & $\mathrm{C}$ \\
\hline 35 & 889 & 20.4 & 11.6 & B & 80 & 978 & 8.6 & 7.7 & B \\
\hline 36 & 1,200 & 13.4 & 9.6 & B & 81 & 1,556 & 14.1 & 10.5 & $\mathrm{C}$ \\
\hline 37 & 1,333 & 11.1 & 9.4 & B & 82 & 978 & 20.6 & 12.7 & B \\
\hline 38 & 1,911 & 8.4 & 7.9 & B & 83 & 1,289 & 14.9 & 10.6 & B \\
\hline 39 & 1,800 & 11.4 & 9.2 & $\mathrm{M}$ & 84 & 1,022 & 21.0 & 12.4 & B \\
\hline 40 & 800 & 17.2 & 11.2 & $\mathrm{M}$ & 85 & 800 & 16.1 & 11.3 & B \\
\hline 41 & 933 & 14.9 & 10.7 & $\mathrm{~B}$ & 86 & 933 & 15.8 & 10.7 & B \\
\hline
\end{tabular}


Table 1. Cont.

\begin{tabular}{cccccccccc}
\hline NO. & $\begin{array}{c}\text { Density } \\
\text { (Stem/ha) }\end{array}$ & $\begin{array}{c}\text { Average } \\
\text { DBH (cm) }\end{array}$ & $\begin{array}{c}\text { Average } \\
\text { Height }(\mathbf{m})\end{array}$ & $\begin{array}{c}\text { Forest } \\
\text { Type }\end{array}$ & NO. & $\begin{array}{c}\text { Density } \\
\text { (Stem/ha) }\end{array}$ & $\begin{array}{c}\text { Average } \\
\text { DBH }(\mathbf{c m})\end{array}$ & $\begin{array}{c}\text { Average } \\
\text { Height }(\mathbf{m})\end{array}$ & $\begin{array}{c}\text { Forest } \\
\text { Type }\end{array}$ \\
\hline 42 & 2,533 & 9.5 & 8.0 & $\mathrm{M}$ & 87 & 400 & 10.1 & 8.5 & $\mathrm{~B}$ \\
43 & 2,711 & 9.3 & 7.9 & $\mathrm{M}$ & 88 & 356 & 15.4 & 11.1 & $\mathrm{~B}$ \\
44 & 1,556 & 12.6 & 9.5 & $\mathrm{M}$ & 89 & 1,156 & 18.0 & 11.7 & $\mathrm{~B}$ \\
45 & 1,600 & 12.5 & 9.4 & $\mathrm{M}$ & 90 & 1,200 & 17.8 & 11.3 & $\mathrm{~B}$ \\
\hline
\end{tabular}

\subsection{Satellite Imagery and GIS Data}

The image data used in this study were acquired by the WorldView-2 satellite on 10 December 2011, during good weather and clear skies. At this time of the year, the leaves of some deciduous tree species had fallen, and some trees were turning yellow, while evergreen tree leaves were fully alive, providing good conditions for tree species identification and classification. The satellite has a panchromatic band $(0.46-0.80 \mu \mathrm{m})$ with $0.5-\mathrm{m}$ ground resolution at nadir and eight multispectral bands with $2.0-\mathrm{m}$ resolution [32]. In addition to the four standard colors, Blue $(0.45-0.51 \mu \mathrm{m})$, Green $(0.51-0.58 \mu \mathrm{m})$, Red $(0.63-0.69 \mu \mathrm{m})$ and Near Infrared $1(0.77-0.90 \mu \mathrm{m})$, four new, additional bands are available: Coastal Blue $(0.40-0.45 \mu \mathrm{m})$, Yellow $(0.59-0.63 \mu \mathrm{m})$, Red-Edge $(0.71-0.75 \mu \mathrm{m})$ and Near Infrared 2 $(0.86-1.04 \mu \mathrm{m})$. The size of the image was 8,868 lines $\times 9,358$ pixels at the nadir with 16-bit data stored, and the geometric projection was UTM WGS 84 Zone 50 North. The image data were ordered as the premium product level, suggesting that the data had been sensor-corrected, ortho-rectified and geo-corrected by the data provider, DigitalGlobe Inc. [33]. The data were atmospherically corrected using the Fast Line-of-Sight Atmospheric Analysis of Spectral Hypercubes (FLAASH) algorithm built in the ENVI 4.8 software. According to DigitalGlobe, the geolocation accuracy of the delivered image ranges from $4.6 \mathrm{~m}$ to $10.7 \mathrm{~m}$ (CE90) [33]. This accuracy was checked by comparing the data to the standard map of the mountain created by an infrared airborne photograph taken in 1991 with an accuracy of $5 \mathrm{~m}$. The two datasets were in good agreement, as verified by matching the special positions, such as the intersections of roads, single buildings and water areas. Consequently, the horizontal accuracy of the WorldView-2 dataset is approximately $5 \mathrm{~m}$.

In this study, geographic data, such as the boundary line of the mountain, forest compartment boundaries, roads and forest base maps were from the ArcGIS (GIS, Geographic Information System) database, which was established in 2002 based on the forest inventory data of 662 plots investigated by a special project in 2001 [34]. The field data for the 90 plots surveyed in September 2011, were inputted into the above database, including stem density, average DBH, average tree height, forest type, dominant species, volume and GPS data for the plot center. These data were used to test the accuracy of the interpreted tree tops and to perform a supervised classification of tree species.

\subsection{Data Analysis}

\subsubsection{Interpretation of Tree Tops}

The research flow chart in Figure 2 provides an overview of the methods. Tree tops were interpreted with the ITC approach using WorldView-2 imagery in PCI Geomatica v9.1 software with 
the ITC Suite $[18,28,35]$. First, preprocessing for tree top interpretations was necessary to normalize the panchromatic band based on its own range in the illumination image, which was performed twice to smooth using an averaging filter of $5 \times 5$ pixels $(2.5$ by $2.5 \mathrm{~m})$ [18,28]. Second, an NDVI (Normalized Difference Vegetation Index) image was generated using the Vegetation Index Image function. Third, a bitmap of the non-vegetation area was automatically created using the NVEG MASK function of the ITC Suite by comparing (normalized or not) the NIR and the visible values [28]. In this step, man-made structures, such as buildings and roads, soil and water zones, were extracted with good results, but some grass areas composed of herbs could not be extracted, because the grasses had similar multispectral characteristics to the forest area; an error in which some forest area was identified as non-vegetation area was generated from the automatic extraction, due to the image acquired in December 2011. These two problems were solved by the following approach: first, the minimum and maximum values of the NDVI and/or panchromatic band were found for the grass and misclassified forest areas (in this study, the panchromatic value of 40 to 80 and the NDVI value of 170 to 195 could be used to separate the grass areas and to correct the misclassified forests, respectively); second, two bitmaps for these areas were established by the THR (Thresholding Image to Bitmap) function; finally, the correct non-forested regions of the image were extracted by the non-vegetation zone plus grass and minus misclassified forest area by the BLO function (Bitmap Logical Operation).

Figure 2. Research flow chart. ITC, individual tree crown.

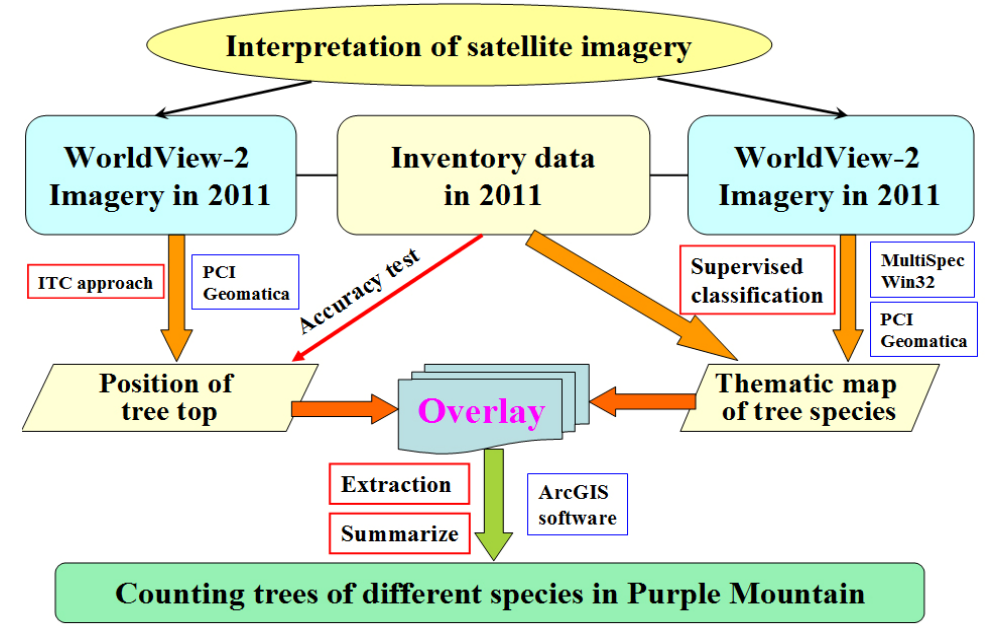

The ITC isolation image was produced by using the valley-following algorithm. Using the normalized panchromatic band and the non-forested mask, this method treats the spectral values as topography, with shaded and darker areas representing valleys and bright pixels delineating the tree crowns [18]. This method produces a bitmap of segments of valley and crown materials in forest areas. A rule-based system follows the boundary of each segment of crown material to create isolations, which are taken to represent tree crowns, while the pixel with the highest gray value at each tree crown is interpreted as the tree top by the local maxima filtering technique [28]. Because of the coverage of canopy trees, small trees in the understory were difficult to interpret $[1,11]$. Therefore, based on the present condition of the surveyed plots, all forests at Purple Mountain were divided into three groups: trees $\geq 10 \mathrm{~cm} \mathrm{DBH}, \geq 15 \mathrm{~cm} \mathrm{DBH}$ and $\geq 20 \mathrm{~cm} \mathrm{DBH}$. We attempted to extract the tops of trees in 
these three groups by using filters with a moving window of $3 \times 3$ pixels $(1.5 \times 1.5 \mathrm{~m}), 5 \times 5$ pixels $(2.5 \times 2.5 \mathrm{~m})$ and $7 \times 7$ pixels $(3.5 \times 3.5 \mathrm{~m})$, respectively, which, in theory, may extract trees with crown diameters of more than $1.5 \mathrm{~m}, 2.5 \mathrm{~m}$ and $3.5 \mathrm{~m}$, respectively.

The interpreted accuracy of tree tops can be calculated by the following formula:

$$
\Phi=\left(1-\left|\mathrm{D}_{\mathrm{I}}-D_{S}\right| / D_{S}\right) \times 100
$$

where $\Phi$ is the interpreted accuracy (\%), $D_{\mathrm{I}}$ is the stem density of trees interpreted by the ITC method and $D_{\mathrm{S}}$ is the stem density of trees in the surveyed plot. The field data for the 90 plots were used to test the accuracy.

\subsubsection{Supervised Classification and Counting for Different Tree Species}

Based on forest inventory data and other information, including photos linked in Google Earth and existing thematic maps, the WorldView-2 imagery of the study area was classified into 16 classes by using a supervised classification process of eight multispectral bands with the Maximum Likelihood algorithm in ERDAS Imagine v8.6 and in MultiSpec Win32. In spite of having attempted to define an exhaustive list of classes and having enhanced the statistics, there will still be some pixels that have a low likelihood of being members of even the most likely class. Though the probability results map will show where these pixels are, the MultiSpec thresholding capability can provide quantitative information about them. For example, if a threshold of $2 \%$ is selected, the threshold level will be calculated, such that $2 \%$ of an ideal Gaussian distribution with the same mean vector and covariance matrix will be thresholded in each class [36]. The lower the threshold value is, the higher the rate of classified pixels, whereas the lower the classified accuracy. The threshold was set at the $2 \%$ default in our study, because the $2 \%$ level had the best classification results compared to other values. Additionally, to overcome the "mixed pixels" problem of the pixel-based classification (i.e., some pixels within a tree crown may be classified into two or more different classes), an object-based supervised classifier (called crown-based classification) was designed for tree species classification in the ITC Suite [28], which was used to generate another thematic map of the tree species in this study. This crown-based classification was completed by the ITCSC (Individual Tree Crown Supervised Classifier) function of the ITC Suite. The ITCSC classified the individual tree crowns (ITCs) of the image into different species using a Maximum-Likelihood (ML) decision rule [28]. The classification was based on comparing the signature of each ITC, one by one, with the ITC-based signatures of the various species. The species signatures were produced by the ITCSSG (Individual Tree Crown Species Signatures Generation) program using the training areas created at the section of the pixel-based classification. Finally, when the tree tops interpretation and the supervised classification processes were completed, all tree tops were annotated with a species attribute from the species thematic map delineated by the crown-based classification using an overlay by the extraction function in ArcGIS v9.2. The total number of trees of different species at Purple Mountain was counted using the summarize function. 


\section{Results}

\subsection{Interpretation of Tree Tops}

In this study, the tree tops of the three groups, $\geq 10 \mathrm{~cm} \mathrm{DBH,} \geq 15 \mathrm{~cm} \mathrm{DBH}$ and $\geq 20 \mathrm{~cm} \mathrm{DBH}$, were extracted using filters with moving windows of $3 \times 3$ pixels, $5 \times 5$ pixels and $7 \times 7$ pixels, respectively. For the total mountain, there were $1,203,970$ trees of DBH over $10 \mathrm{~cm}$, and the accuracy of interpretation was $73.68 \pm 15.14 \%$ (average value and standard deviation) averaged for the 90 plots. The number of trees $\geq 15 \mathrm{~cm}$ and $\geq 20 \mathrm{~cm} \mathrm{DBH}$ is 727,887 and 548,919 , with an average accuracy of $68.74 \pm 17.21 \%$ and $71.92 \pm 18.03 \%$, respectively.

According to the composition of tree species, the 90 plots were divided into three types: broad-leaved forest, coniferous forest and mixed forest. The average interpretation accuracies of the different forest types in the three groups were calculated as shown in Figure 3 (average value and standard deviation). In the broad-leaved forest, the accuracy in the $\mathrm{DBH} \geq 10 \mathrm{~cm}$ layer was higher than that in the $\mathrm{DBH} \geq 15 \mathrm{~cm}$ layer and the $\mathrm{DBH} \geq 20 \mathrm{~cm}$ layer, indicating that with the growth of broad-leaved trees, the tree tops become difficult to identify, in contrast to coniferous forests [18]. There is no significant difference in accuracy between the three groups for mixed forest.

Figure 3. The difference in accuracy between forest types for the three groups.

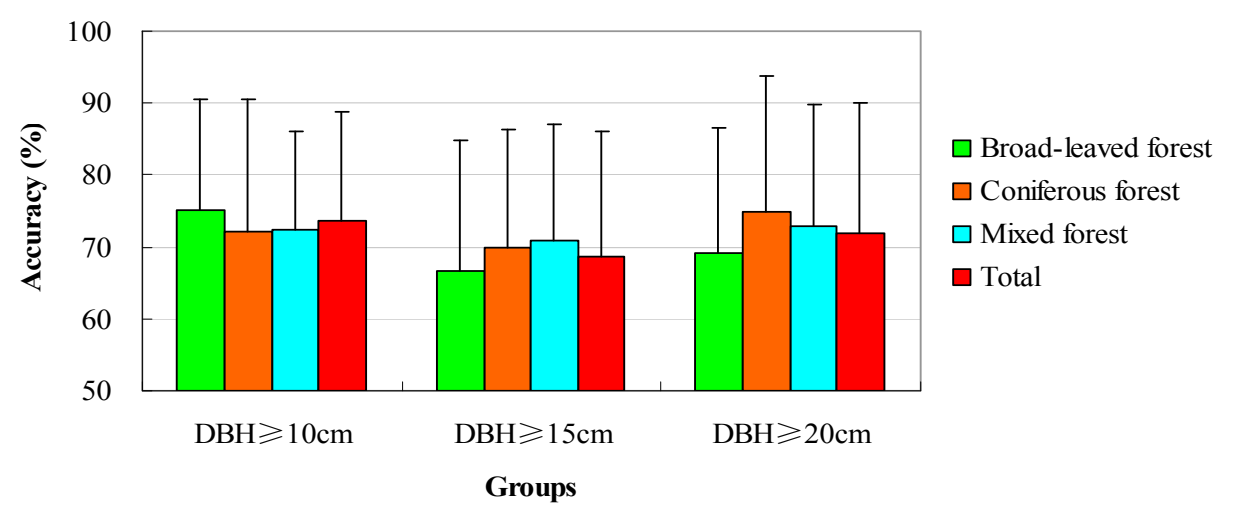

Figure 4. Regression of accuracy and stem density of the surveyed plots. (a) $3 \times 3$ pixels for $\mathrm{DBH} \geq 10 \mathrm{~cm}$; (b) $5 \times 5$ pixels for $\mathrm{DBH} \geq 15 \mathrm{~cm}$; (c) $7 \times 7$ pixels for $\mathrm{DBH} \geq 20 \mathrm{~cm}$.

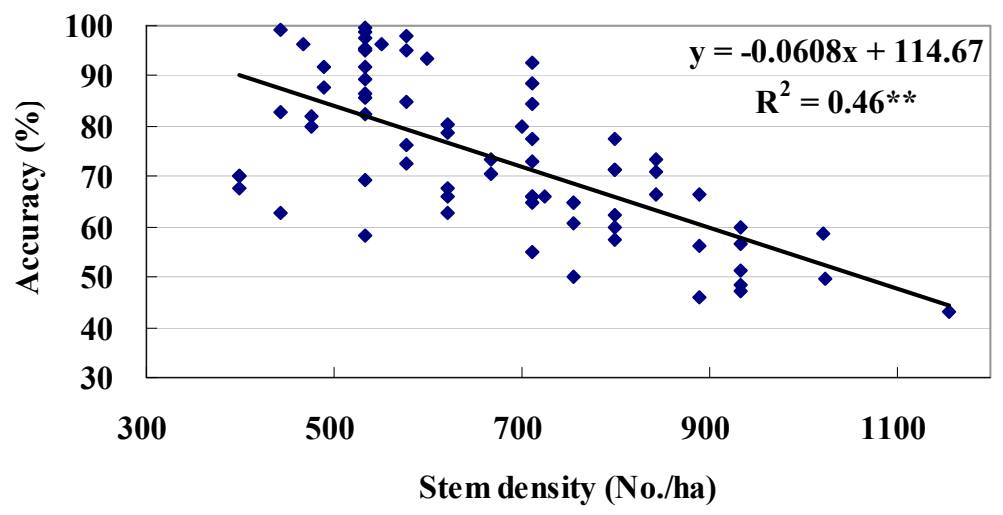

(a) 
Figure 4. Cont.

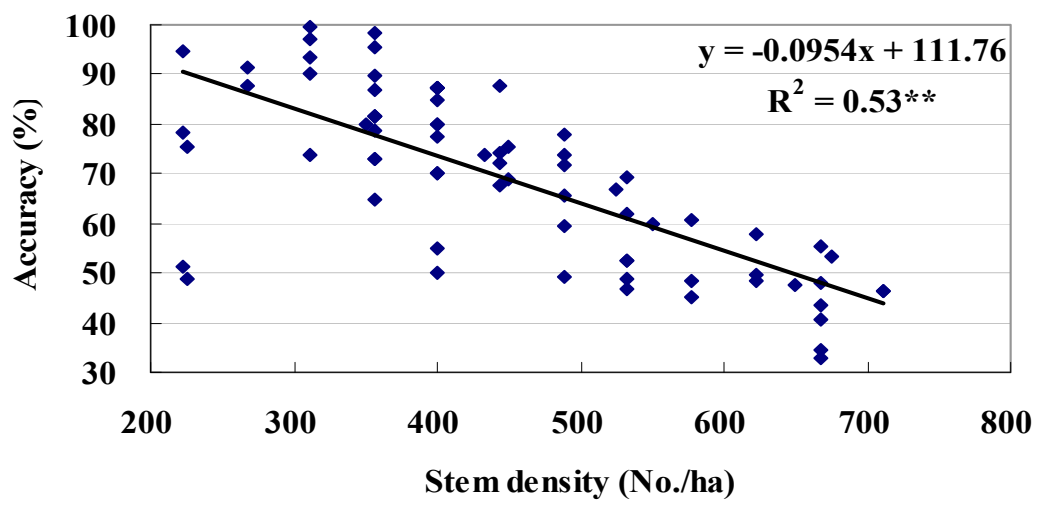

(b)

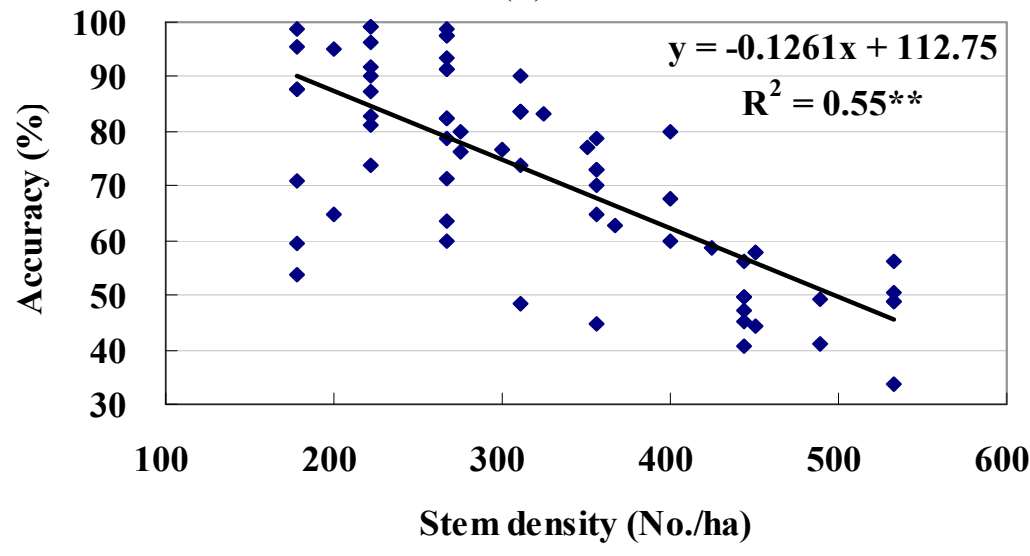

(c)

In addition, the effects of stem density in the surveyed plots on interpretation accuracy were analyzed. The regressions of stem density and interpreted accuracy were performed as shown in Figure 4. The results indicate that the accuracy decreases as the stem density increases, because the chance of overlap between crowns increases with incremental stem density.

\subsection{Pixel-Based Supervised Classification of Tree Species}

Based on forest inventory data and other information, a supervised classification was performed on the WorldView-2 imagery with eight multispectral bands in the MultiSpec Win32 software. The imagery was classified into two types of land cover with a total of 16 classes. One of these types was non-forested area with five classes: building, water, soil, road and grass; and the other was forest area: open forest, eight main tree species, bamboo and shadow (Figure 5). The open forest was defined as the zones composed of nursery, shrubland or sparse trees. The shadow class mainly formed from the northern regions neighboring mountain ridges, where the abrupt slope and trees with fallen leaves with small sizes and low density led to the shaded and darker areas. 
Figure 5. Distribution of 16 classes classified by MultiSpec Win32 for eight multispectral bands. Of: open forest; $\mathrm{Cd}$ : Cedrus deodara; Mg: Metasequoia glyptostroboides; Pco: Platycladus orientalis; Pm: Pinus massoniana; Pe: Pinus elliottii; Pno: Platanus orientalis; Ba: bamboo; Lf: Liquidambar formosana; Qa: Quercus acutissima; Sh: shadow.

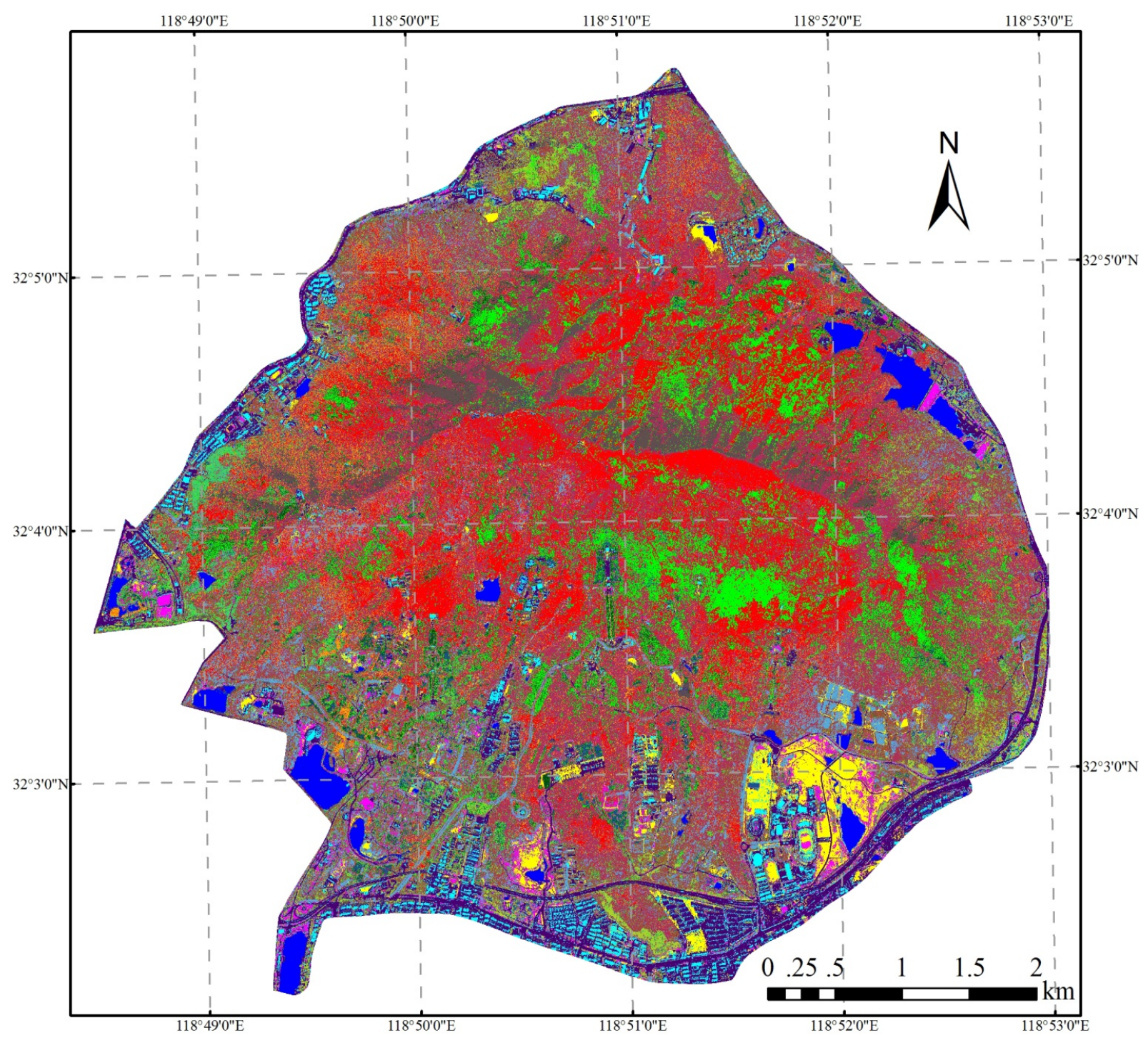

Legend

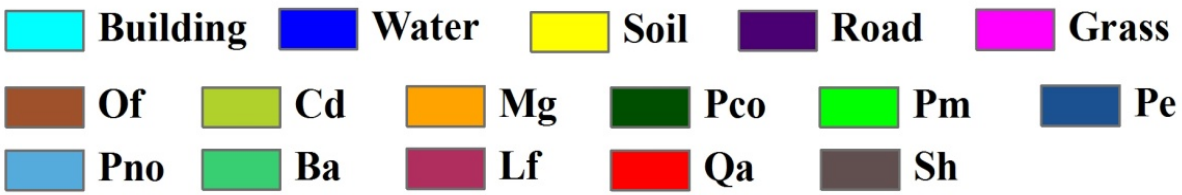

In the process of classification, 282 training areas with a total number of 194,117 pixels $\left(4.0 \mathrm{~m}^{2} /\right.$ pixel) were created for the 16 classes (for a detailed number of each class, see Table 2$)$. Using the mean digital number (DN, representing the reflectance of the objects on sunshine) of the test pixels of each class for all multi-color bands, a straight-line map was used to compare the spectral characteristics of the different classes (Figure 6). Band DNs for the spectral values were highest for 
Green (ranging $0.51-0.58 \mu \mathrm{m}$ ), either in non-forested areas or forest areas, and lowest for Red $(0.63-0.69 \mu \mathrm{m})$ for most of the classes. The mean DNs of the Blue band $(0.45-0.51 \mu \mathrm{m})$ for most of the classes in non-forest regions were higher than those of other bands. However, most tree species had nearly equal spectral values in the Blue, Red-Edge, NIR1 and NIR2 bands. In addition, the water and shadow classes had similar trend lines, with the lowest DN value in band NIR2. The DN values of broad-leaved trees were greater than those of conifers, and Platanus orientalis was the highest for most bands. Although the DNs of most bands differed markedly between broad-leaved and coniferous trees, little discrepancy was found in some conifers, such as Platycladus orientalis and Pinus massoniana, which was disadvantageous for classifying them. Additionally, the statistical test of separability using the Transformed Divergence method indicated a good separability between most of the classes (Table 3).

Figure 6. Comparison of the mean digital number $(\mathrm{DN})$ values of different classes using a line chart. The abbreviations are the same as in Figure 5. (a) Non-forest area; (b) Forest area.

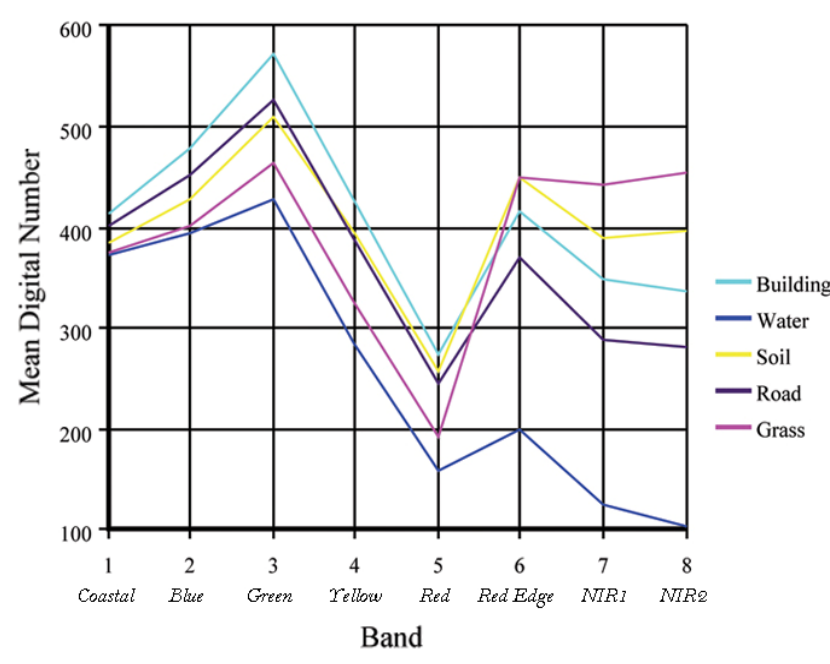

(a)

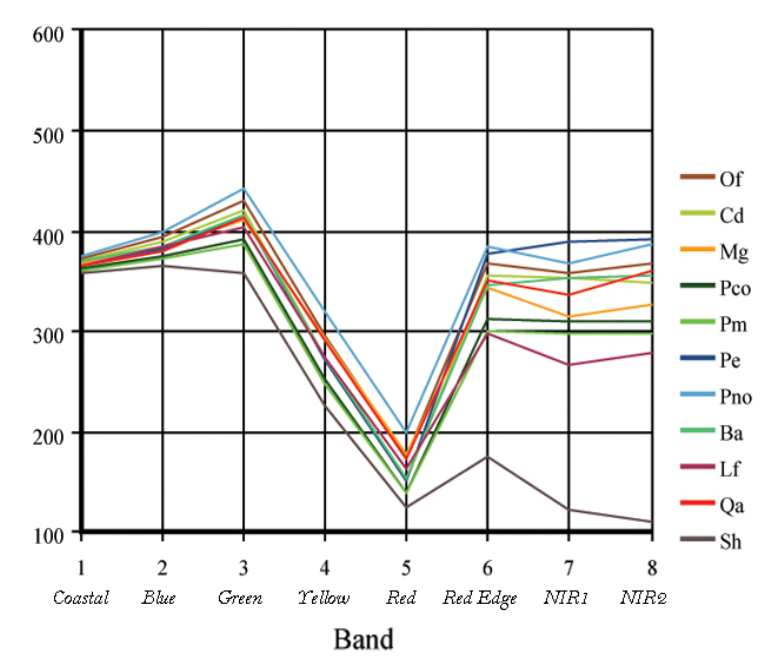

(b)

The confusion matrix for the test areas for the 16 classes using WorldView-2 imagery with eight bands by MultiSpec Win32 is shown in Table 2. Non-forested areas are typically classified with high accuracy, with the exception of road type, because the spectral signatures of many road pixels are similar to those of buildings and were misclassified as buildings. Regarding tree species, the confusion matrix indicated the dominant species in the canopy layer, Pinus massoniana and Quercus acutissima, which were classified at $80.6 \%$ and $93.0 \%$, respectively. However, the accuracy of another dominant species, Liquidambar formosana, was relatively low at $67.5 \%$, because it was in the subdominant layer and many individuals were covered by Quercus acutissima. By contrast, some species were misclassified with low accuracy. For example, Platycladus orientalis and Platanus orientalis were misclassified into Pinus massoniana and open forest, respectively, mainly due to their low proportion and because most of the forest in the study area was composed of uneven-aged mixed forest with a complex spatial structure. 
Table 2. Confusion matrix for the 16 classes using WorldView-2 imagery with eight bands by MultiSpec Win32.

\begin{tabular}{|c|c|c|c|c|c|c|c|c|c|c|c|c|c|c|c|c|c|c|c|}
\hline $\begin{array}{c}\text { Class } \\
\text { Name* }\end{array}$ & $\begin{array}{l}\text { Class } \\
\text { NO. }\end{array}$ & 1 & 2 & 3 & 4 & 5 & 6 & 7 & 8 & 9 & 10 & 11 & 12 & 13 & 14 & 15 & 16 & $\begin{array}{l}\text { Number } \\
\text { Samples }\end{array}$ & $\begin{array}{c}\text { Producer's } \\
\text { Accuracy } \\
(\%)\end{array}$ \\
\hline Building & 1 & 12,819 & 49 & 103 & 6,930 & 3 & 36 & 10 & 2 & 0 & 0 & 1 & 1 & 2 & 3 & 6 & 0 & 22,966 & 55.8 \\
\hline Water & 2 & 4 & 81,143 & 0 & 5 & 0 & 0 & 0 & 0 & 611 & 8 & 82 & 0 & 5 & 0 & 0 & 0 & 83,059 & 97.7 \\
\hline Soil & 3 & 185 & 0 & 11,067 & 23 & 17 & 20 & 0 & 0 & 0 & 0 & 0 & 4 & 0 & 0 & 0 & 0 & 11,774 & 94.0 \\
\hline Road & 4 & 424 & 6 & 38 & 8,299 & 2 & 2 & 0 & 0 & 0 & 0 & 0 & 0 & 0 & 0 & 0 & 0 & 9,037 & 91.8 \\
\hline Grass & 5 & 4 & 0 & 6 & 0 & 2,739 & 237 & 52 & 6 & 0 & 0 & 86 & 192 & 33 & 9 & 106 & 0 & 3,607 & 75.9 \\
\hline Of & 6 & 5 & 5 & 170 & 14 & 965 & 8,688 & 526 & 96 & 145 & 159 & 708 & 2,883 & 1,140 & 1,580 & 120 & 0 & 17,875 & 48.6 \\
\hline $\mathrm{Cd}$ & 7 & 0 & 0 & 0 & 1 & 5 & 13 & 1,132 & 0 & 80 & 31 & 27 & 0 & 118 & 3 & 0 & 0 & 1,419 & 79.8 \\
\hline $\mathrm{Mg}$ & 8 & 0 & 1 & 0 & 0 & 0 & 4 & 0 & 1,215 & 0 & 5 & 0 & 49 & 4 & 132 & 93 & 0 & 1,543 & 78.7 \\
\hline Pco & 9 & 0 & 2 & 0 & 0 & 3 & 6 & 33 & 2 & 829 & 300 & 103 & 0 & 48 & 9 & 3 & 0 & 1,352 & 61.3 \\
\hline $\mathrm{Pm}$ & 10 & 0 & 8 & 0 & 0 & 3 & 55 & 445 & 3 & 664 & 4,306 & 144 & 1 & 89 & 73 & 40 & 15 & 5,902 & 73.0 \\
\hline $\mathrm{Pe}$ & 11 & 1 & 0 & 0 & 0 & 68 & 50 & 441 & 7 & 289 & 190 & 1,144 & 0 & 267 & 7 & 33 & 0 & 2,570 & 44.5 \\
\hline Pno & 12 & 1 & 0 & 5 & 2 & 27 & 102 & 0 & 116 & 0 & 0 & 0 & 2,583 & 1 & 164 & 52 & 0 & 3,099 & 83.3 \\
\hline $\mathrm{Ba}$ & 13 & 0 & 1 & 0 & 0 & 30 & 87 & 239 & 4 & 135 & 107 & 152 & 0 & 2,365 & 11 & 29 & 0 & 3,178 & 74.4 \\
\hline $\mathrm{Lf}$ & 14 & 10 & 2 & 0 & 0 & 2 & 233 & 0 & 415 & 12 & 86 & 1 & 141 & 27 & $\mathbf{6 , 4 2 7}$ & 136 & 24 & 7,694 & 83.5 \\
\hline $\mathrm{Qa}$ & 15 & 8 & 0 & 0 & 0 & 37 & 137 & 0 & 1,076 & 30 & 68 & 37 & 548 & 29 & 1061 & 8,265 & 0 & 11,662 & 70.9 \\
\hline Sh & 16 & 0 & 10 & 0 & 0 & 0 & 0 & 0 & 0 & 4 & 84 & 0 & 0 & 0 & 39 & 2 & 7,033 & 7,380 & 95.3 \\
\hline Total & & 13,461 & 81,227 & 11,389 & 15,274 & 3,901 & 9,670 & 2,878 & 2,942 & 2,799 & 5,344 & 2,485 & 6,402 & 4,128 & 9,518 & 8,885 & 7,072 & 194,117 & \\
\hline $\begin{array}{c}\text { User's Accuracy } \\
(\%)\end{array}$ & & 95.2 & 99.9 & 97.2 & 54.3 & 70.2 & 89.8 & 39.3 & 41.3 & 29.6 & 80.6 & 46.0 & 40.3 & 57.3 & 67.5 & 93.0 & 99.4 & & \\
\hline
\end{tabular}

Notes: Overall Class Performance $(160054 / 194117)=82.5 \%$; Kappa Statistic $(X 100)=77.9 \%$; Kappa Variance = 0.000001. * Of: open forest; Cd: Cedrus deodara; Mg: Metasequoia glyptostroboides; Pco: Platycladus orientalis; Pm: Pinus massoniana; Pe: Pinus elliottii; Pno: Platanus orientalis; Ba: bamboo; Lf: Liquidambar formosana; Qa: Quercus acutissima; Sh: shadow. 
Table 3. The statistical test of the Signature Separability for the 16 classes using the Transformed Divergence method.

\begin{tabular}{|c|c|c|c|c|c|c|c|c|c|c|c|c|c|c|c|c|c|}
\hline Signature Name* & Class NO. & 1 & 2 & 3 & 4 & 5 & 6 & 7 & 8 & 9 & 10 & 11 & 12 & 13 & 14 & 15 & 16 \\
\hline Building & 1 & 0 & 2,000 & 2,000 & 2,000 & 2,000 & 2,000 & 2,000 & 2,000 & 2,000 & 2,000 & 2,000 & 2,000 & 2,000 & 2,000 & 2,000 & 2,000 \\
\hline Water & 2 & 2,000 & 0 & 2,000 & 2,000 & 2,000 & 2,000 & 2,000 & 2,000 & 2,000 & 2,000 & 2,000 & 2,000 & 2,000 & 2,000 & 2,000 & 2,000 \\
\hline Soil & 3 & 2,000 & 2,000 & 0 & 1,998 & 1,974 & 1,988 & 2,000 & 2,000 & 2,000 & 2,000 & 2,000 & 1,991 & 2,000 & 2,000 & 1,999 & 2,000 \\
\hline Road & 4 & 2,000 & 2,000 & 1,998 & 0 & 2,000 & 2,000 & 2,000 & 2,000 & 2,000 & 2,000 & 2,000 & 2,000 & 2,000 & 2,000 & 2,000 & 2,000 \\
\hline Grass & 5 & 2,000 & 2,000 & 1,974 & 2,000 & 0 & 1,663 & 1,996 & 1,997 & 2,000 & 1,999 & 1,911 & 1,953 & 1,972 & 1,998 & 1,924 & 2,000 \\
\hline Of & 6 & 2,000 & 2,000 & 1,988 & 2,000 & 1,663 & 0 & 1,943 & 1,870 & 1,994 & 1,986 & 1,776 & 1,619 & 1,775 & 1,775 & 1,810 & 2,000 \\
\hline $\mathrm{Cd}$ & 7 & 2,000 & 2,000 & 2,000 & 2,000 & 1,996 & 1,943 & 0 & 2,000 & 1,702 & 1,566 & 1,364 & 2,000 & 1,102 & 1,990 & 1,997 & 2,000 \\
\hline $\mathrm{Mg}$ & 8 & 2,000 & 2,000 & 2,000 & 2,000 & 1,997 & 1,870 & 2,000 & 0 & 2,000 & 1,999 & 1,999 & 1,643 & 1,997 & 1,410 & 1,430 & 2,000 \\
\hline Pco & 9 & 2,000 & 2,000 & 2,000 & 2,000 & 2,000 & 1,994 & 1,702 & 2,000 & 0 & 902 & 1,346 & 2,000 & 1,518 & 1,985 & 1,998 & 2,000 \\
\hline $\mathrm{Pm}$ & 10 & 2,000 & 2,000 & 2,000 & 2,000 & 1,999 & 1,986 & 1,566 & 1,999 & 902 & 0 & 1,543 & 2,000 & 1,599 & 1,946 & 1,994 & 2,000 \\
\hline $\mathrm{Pe}$ & 11 & 2,000 & 2,000 & 2,000 & 2,000 & 1,911 & 1,776 & 1,364 & 1,999 & 1,346 & 1,543 & 0 & 2,000 & 968 & 1,991 & 1,977 & 2,000 \\
\hline Pno & 12 & 2,000 & 2,000 & 1,991 & 2,000 & 1,953 & 1,619 & 2,000 & 1,643 & 2,000 & 2,000 & 2,000 & 0 & 2,000 & 1,629 & 1,633 & 2,000 \\
\hline $\mathrm{Ba}$ & 13 & 2,000 & 2,000 & 2,000 & 2,000 & 1,972 & 1,775 & 1,102 & 1,997 & 1,518 & 1,599 & 968 & 2,000 & 0 & 1,971 & 1,984 & 2,000 \\
\hline $\mathrm{Lf}$ & 14 & 2,000 & 2,000 & 2,000 & 2,000 & 1,998 & 1,775 & 1,990 & 1,410 & 1,985 & 1,946 & 1,991 & 1,629 & 1,971 & 0 & 1,730 & 2,000 \\
\hline Qa & 15 & 2,000 & 2,000 & 1,999 & 2,000 & 1,924 & 1,810 & 1,997 & 1,430 & 1,998 & 1,994 & 1,977 & 1,633 & 1,984 & 1,730 & 0 & 2,000 \\
\hline Sh & 16 & 2,000 & 2,000 & 2,000 & 2,000 & 2,000 & 2,000 & 2,000 & 2,000 & 2,000 & 2,000 & 2,000 & 2,000 & 2,000 & 2,000 & 2,000 & 0 \\
\hline
\end{tabular}

Notes: Distance measure: Transformed Divergence; using layers: 1, 2, 3, 4, 5, 6, 7, 8; best average separability: 1,906.84; combination: 1, 2, 3, 4, 5, 6, 7, 8.

* Of: open forest; Cd: Cedrus deodara; Mg: Metasequoia glyptostroboides; Pco: Platycladus orientalis; Pm: Pinus massoniana; Pe: Pinus elliottii; Pno: Platanus orientalis; Ba: bamboo; Lf:

Liquidambar formosana; Qa: Quercus acutissima; Sh: shadow. 
MultiSpec Win32 is the common software for land cover and forest classification and has been used for forest studies worldwide free of charge. ERDAS Imagine is the comprehensive software available for processing remote sensing images, such as geometric and ortho correction, image enhancement and classification and integration with GIS (Geographic Information System). In this study, using the same training areas, a supervised classification on the same WorldView-2 image with eight multispectral bands was completed by ERDAS Imagine 8.6. Although the classified accuracies of Cedrus deodara and Metasequoia glyptostroboides obtained by ERDAS were higher than those determined by MultiSpec, most of the class accuracies determined by MultiSpec were better than those determined by ERDAS, with an average increment of $1.8 \%$ for the 16 classes (Figure 7). Therefore, we selected the results classified by MultiSpec Win32 for the output thematic map and to conduct the subsequent study. In addition, to clarify whether the four additional bands of WorldView-2 could improve the classification accuracy significantly compared to the four standard bands, the object image with the four standard bands (Blue, Green, Red, and NIR1) was classified again using the same test pixels by MultiSpec. The results indicated that the classified accuracies of the 16 classes obtained by using all of the multispectral bands were higher than those obtained by using only the four standard bands. The increments ranged from $0.1 \%$ for the water class to $17.0 \%$ for Metasequoia glyptostroboides, with an average value of $4.8 \%$ for the 16 classes (Figure 7).

Figure 7. Spider chart representing the user accuracies for different classification approaches. The abbreviations are the same as in Figure 5.

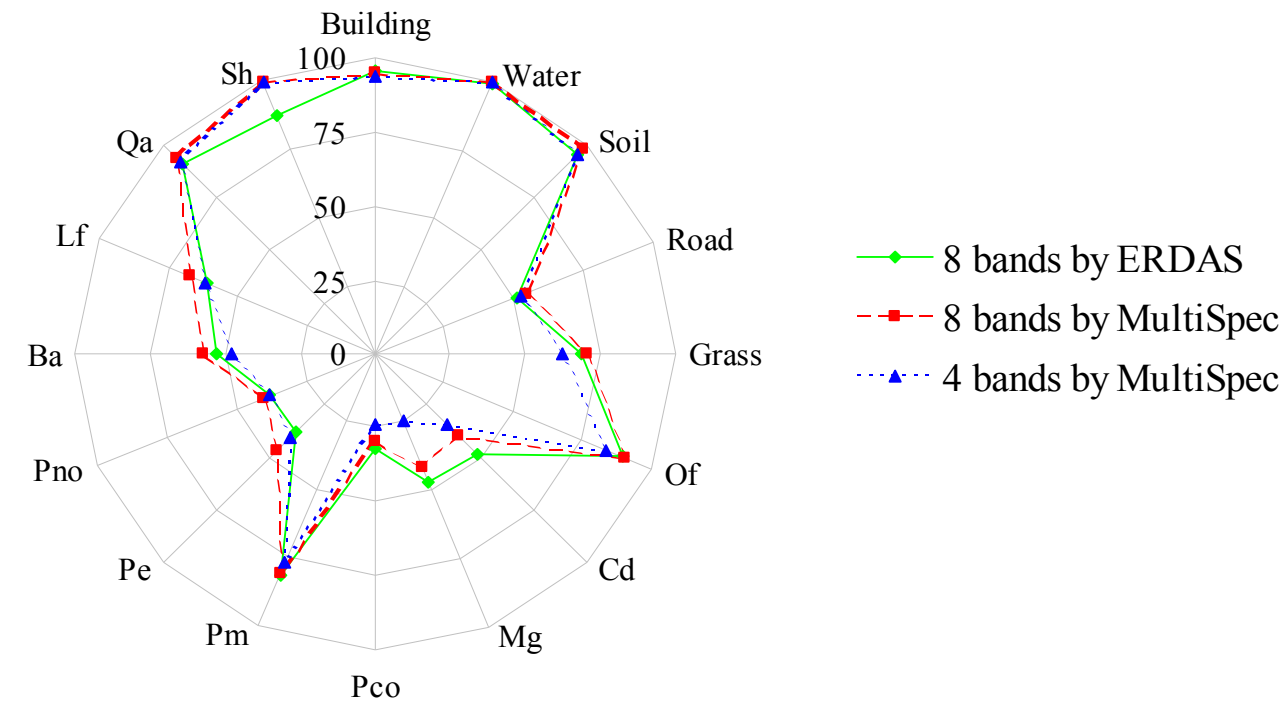

\subsection{Object-Based Supervised Classification of Tree Species}

For the purpose of avoiding the "mixed pixels" effect of the pixel-based classification, a crown-based supervised classification was performed on the forest areas with eight multispectral bands in PCI Geomatica v9.1 with the ITC Suite. As a consequence, with a magnified area, the crown-based thematic map of tree species was generated and documented in Figure 8 by overlaying the non-forest classes produced by the pixel-based classification. When the object-based classification was completed, a total number of 500 random sample trees were used for the accuracy assessment. The 500 sample 
points were generated by the stratified random rule, and the minimum number of each species was 30 . Then, all sample trees were assigned their reference classes based on forest inventory data and other additional information, including photos linked in Google Earth and existing thematic maps. Finally, an accuracy report was generated and displayed in Table 4. The results indicated that the ITC-based classification was much better than the pixel-based classification for the forested area, although the overall accuracy of the latter was slightly higher than that of the former, because the overall accuracy for the pixel-based classification included the non-forested classes, such as water, building and soil, with very good classified results. The improvements of the object- to pixel-based classification ranged from $-1.6 \%$ for the open forest class to $34.3 \%$ for Metasequoia glyptostroboides, with an average value of $20.3 \%$ for the 10 classes.

Figure 8. Distribution of tree species classified by the crown-based approach for eight multispectral bands. (a) the magnified area displayed by delineated tree crowns overlaying the panchromatic band; (b) the magnified area displayed by R: G: B = 7(NIR1): 5(Red): 2(Blue); (c) the magnified area displayed by object-based classified tree crowns overlaying the panchromatic band; (d) the crown-based classification map of tree species at Purple Mountain by overlaying the non-forested classes. The abbreviations are the same as in Figure 5.

(a)

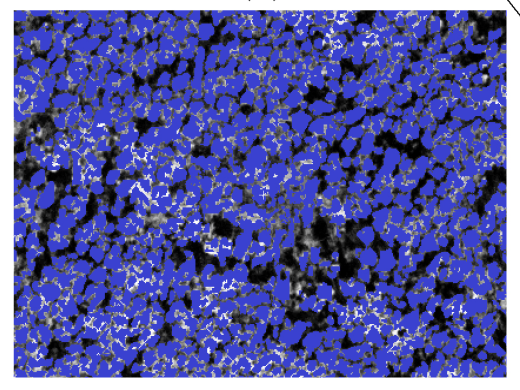

(b)

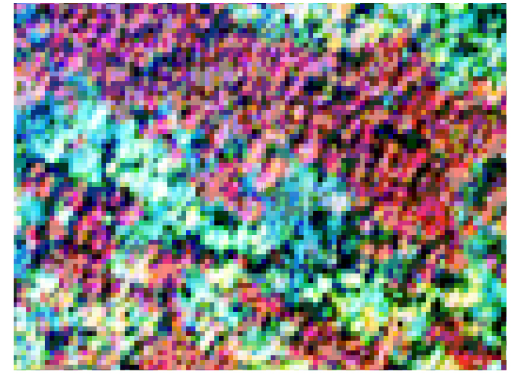

(c)

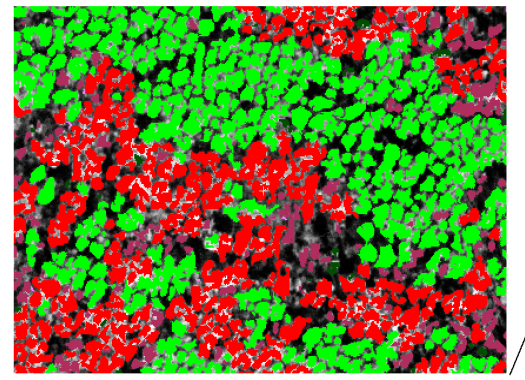

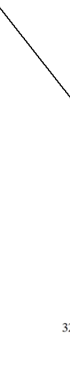

$(d)$

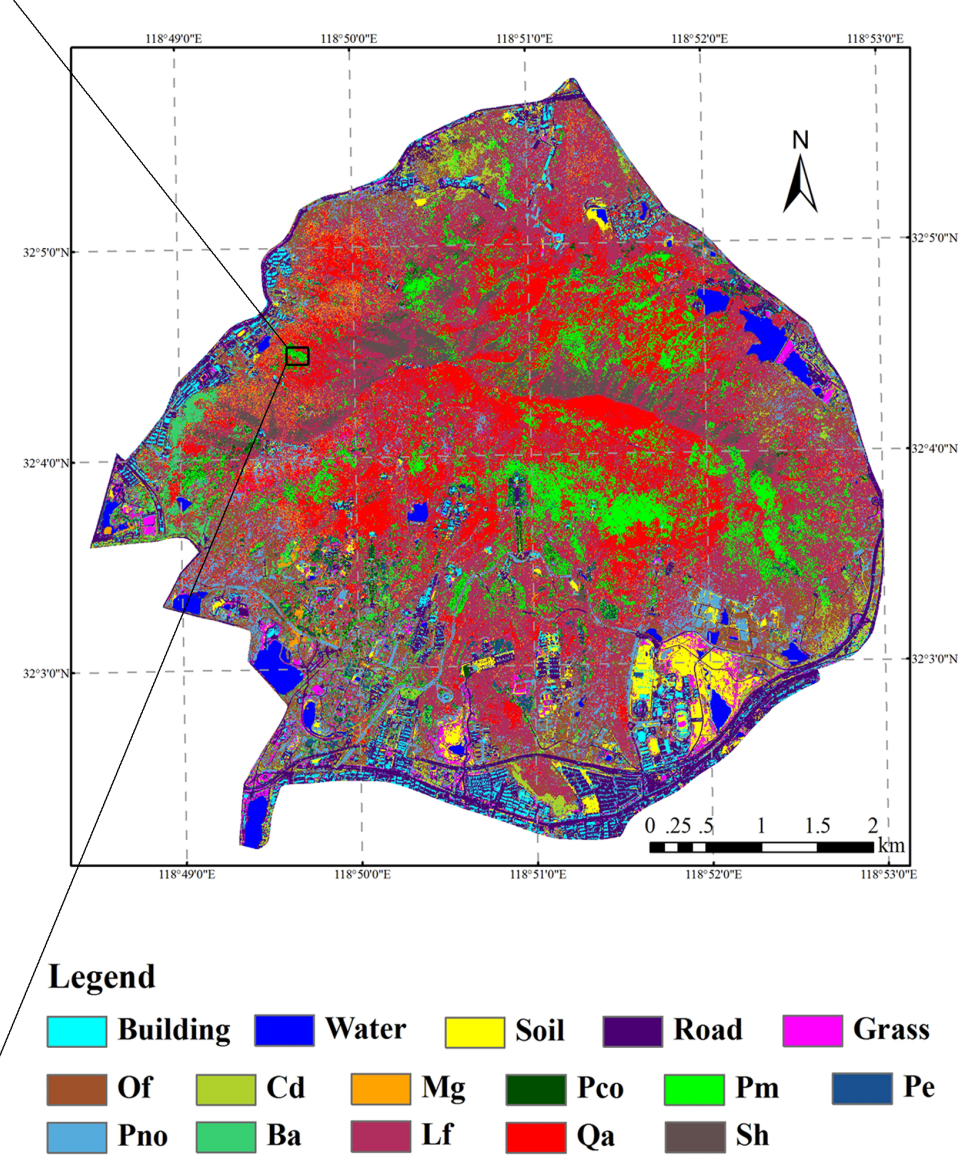


Table 4. Error matrix for the 10 classes classified by the ITC-based classification approach.

\begin{tabular}{ccccccccccccc}
\hline Class Name * & Of & Cd & Mg & Pco & Pm & Pe & Pno & Ba & Lf & Qa & $\begin{array}{c}\text { Number } \\
\text { Samples }\end{array}$ & $\begin{array}{c}\text { Producer's } \\
\text { Accuracy (\%) }\end{array}$ \\
\hline Of & $\mathbf{3 0}$ & 0 & 1 & 0 & 0 & 0 & 1 & 0 & 1 & 0 & 33 & 90.9 \\
Cd & 0 & $\mathbf{2 7}$ & 1 & 2 & 2 & 2 & 1 & 2 & 0 & 0 & 37 & 73.0 \\
Mg & 1 & 0 & $\mathbf{3 4}$ & 0 & 0 & 0 & 5 & 0 & 5 & 0 & 45 & 75.6 \\
Pco & 0 & 5 & 0 & $\mathbf{1 9}$ & 1 & 4 & 0 & 1 & 0 & 0 & 30 & 63.3 \\
Pm & 0 & 1 & 0 & 2 & $\mathbf{5 7}$ & 2 & 0 & 2 & 0 & 1 & 65 & 87.7 \\
Pe & 0 & 1 & 1 & 3 & 3 & $\mathbf{3 3}$ & 0 & 1 & 0 & 0 & 42 & 78.6 \\
Pno & 2 & 2 & 4 & 0 & 0 & 0 & $\mathbf{3 4}$ & 0 & 8 & 0 & 50 & 68.0 \\
Ba & 0 & 2 & 0 & 1 & 2 & 2 & 1 & $\mathbf{2 2}$ & 0 & 1 & 31 & 71.0 \\
Lf & 1 & 1 & 4 & 3 & 1 & 0 & 4 & 0 & $\mathbf{7 1}$ & 2 & 87 & 81.6 \\
Qa & 0 & 0 & 0 & 1 & 0 & 0 & 0 & 0 & 1 & $\mathbf{7 8}$ & 80 & 97.5 \\
Total & 34 & 39 & 45 & 31 & 66 & 43 & 46 & 28 & 86 & 82 & 500 & \\
User's & 88.2 & 69.2 & 75.6 & 61.3 & 86.4 & 76.7 & 73.9 & 78.6 & 82.6 & 95.1 & & \\
Accuracy (\%) & & & & & & & & & & \\
\hline
\end{tabular}

Notes: Overall classification accuracy $(405 / 500)=81.0 \%$; Kappa Statistic $(X 100)=76.3 \%$; Kappa Variance $=0.000001$.

* Of: open forest; Cd: Cedrus deodara; Mg: Metasequoia glyptostroboides; Pco: Platycladus orientalis; Pm: Pinus massoniana;

Pe: Pinus elliottii; Pno: Platanus orientalis; Ba: bamboo; Lf: Liquidambar formosana; Qa: Quercus acutissima.

\subsection{Counting Trees of Different Species in the Study Area}

In this study, using an overlay from the extraction function in ArcGIS v9.2, all tree tops extracted by the ITC method were annotated with species attributes from the thematic map classified by the crown-based approach using the WorldView-2 image with eight multispectral bands. The total number of trees of different species at Purple Mountain was counted using the summarize function (Figure 9).

Figure 9. Tree count of different species at Purple Mountain.

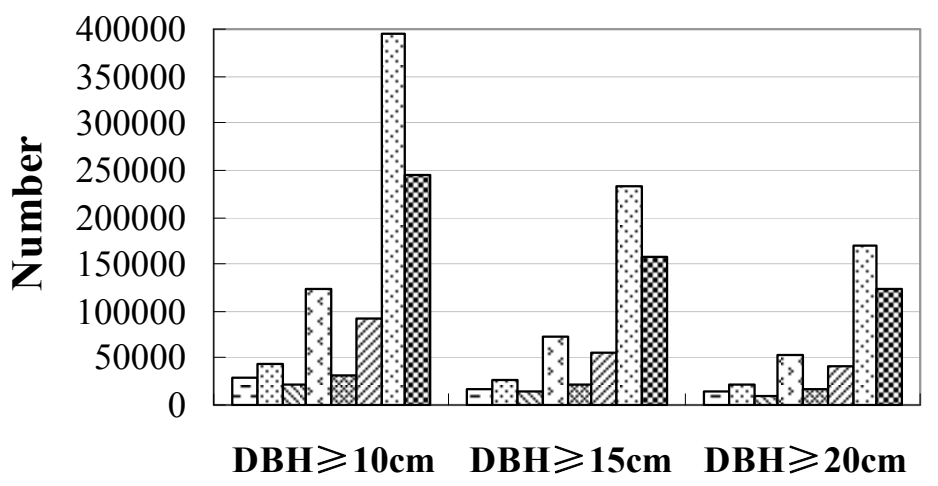

$\square$ Cedrus deodara

圈 Metasequoia glyptostroboides

\$ Platycladus orientalis

$\checkmark$ Pinus massoniana

图 Pinus elliottii

$\checkmark$ Platanus orientalis

$\checkmark$ Liquidambar formosana

Q Quercus acutissima

Groups

The count indicated that the density of the forest in the study area was mainly dominated by Liquidambar formosana and Quercus acutissima in three layers. Pinus massoniana was the dominant species compared with other coniferous species. The results were in accordance with forest inventory data. 


\section{Discussions}

In modern forest management, pure stands are replaced by heterogeneous, mixed stands. Therefore, spatially detailed forest information over large areas is of great importance. The traditional forest inventory method using sample plotting is nearly impossible to accomplish due to its low accuracy and scale limitation. Therefore, enhanced methods are required to obtain spatially explicit information on tree species composition and distribution patterns [2]. This study attempted to acquire forest resource information at the individual tree level by using remote sensing techniques on a large scale.

Tree tops were first interpreted by the ITC method. This approach is very effective for extracting tree tops of even-aged single forests using a filter of a moving window with a single size. For a large forest composed of uneven-aged stands with different tree crown sizes, the homogeneity function of the ITC Suite can be used to separate young tree areas from mature forests [1,24]; the tops of small and large-sized trees can then be interpreted by using filters with different moving window sizes on small and large tree areas, respectively. However, because cutting has been forbidden since the 1980s, there are few stands of a single species or size distributed at Purple Mountain today, and most forests have a complex spatial structure that is difficult to interpret using a filter with a fixed moving window. Therefore, the forests in the study area were divided into three groups: trees $\geq 10 \mathrm{~cm} \mathrm{DBH}$, $\geq 15 \mathrm{~cm} \mathrm{DBH}$ and $\geq 20 \mathrm{~cm}$ DBH. The tree tops in the three groups were then extracted by using filters with a moving window of $3 \times 3$ pixels $(1.5 \times 1.5 \mathrm{~m}), 5 \times 5$ pixels $(2.5 \times 2.5 \mathrm{~m})$ and $7 \times 7$ pixels $(3.5 \times 3.5 \mathrm{~m})$, respectively, which, in theory, should extract trees with crown diameters of greater than $1.5 \mathrm{~m}, 2.5 \mathrm{~m}$ and $3.5 \mathrm{~m}$, respectively.

Although the tree crowns were delineated using the individual tree crown approach based on the DBH knowledge of the 90 plots, the interpreted results of the tree crowns and tree tops are independent of the DBH information. Consequently, this approach can also be used to delineate the trees in the areas with no DBH information. In the even-aged forests, the trees can be easily mapped using a fixed moving window, because of the approximately same crown sizes. Additionally, the trees in the areas having a mixed DBH class can be delineated using a similar method as our study. The filter window size(s) can be determined by roughly estimating the tree crown sizes combining the spatial resolution of the remotely sensed data. When the tree crown delineations were completed, the DBH inversion of the interpreted trees may be true using the correlations between the tree crowns and DBHs of observed trees. This topic will be verified in the next study using the 10 large-sized plots investigated in May 2012, in which the detailed position information of the individual trees was recorded in addition to the crown sizes.

In addition, we selected the entire mountain, which has an area of approximately $30 \mathrm{~km}^{2}$, as the research study area and established 90 plots distributed in different forest types to test accuracy. Due to time limitations and the large number of plots, we only measured DBH and the height of the trees $\geq 5 \mathrm{~cm} \mathrm{DBH}$ and did not include the coordinates of every tree. The center of every plot was noted by GPS (Garmin MAP 60CS, accuracy $\pm 3 \mathrm{~m}$ ) and as sample points. We considered that the observed stem density in sample points could represent the condition of forest stands around sample points. For extracted trees, the densities in every central point were calculated by the buffer function in ArcGIS v9.2. Finally, we verified the agreement of the observed and estimated tree densities in every central point and calculated the interpreted accuracy. We plan to verify the agreement of the observed and estimated trees individually by creating some large size plots in our next study. 
WorldView-2 was expected to have great potential for forest studies, because the satellite has higher spatial resolution and can provide more abundant multispectral information compared with traditional sensors. The findings of our study suggested that the four new bands (Coastal, Yellow, Red-Edge and NIR2) of the WorldView-2 have a positive effect on the species classification. The classified accuracies of the 16 classes obtained using all of the eight multispectral bands were higher than those obtained using only the four standard bands. The improvements ranged from $0.1 \%$ for the water class to $17.0 \%$ for Metasequoia glyptostroboides, with an average value of $4.8 \%$ for the 16 classes.

At Purple Mountain, most stands have a complex spatial structure, with more than two layers and many regenerated species that differ from those of the canopy trees distributed in understories and the gaps between tree crowns, complicating the identification of individual tree crowns and species. The broad-leaved species, Quercus acutissima, the most dominant species in the canopy layer, was classified with good user accuracy. In the late 1970s, many large Pinus massoniana trees, the dominant coniferous species, were damaged by pine wilt disease. Broad-leaved trees, including Quercus acutissima and Pistacia chinensis, successfully invaded the gaps and had good growth. As a result, Pinus massoniana has been classified with an accuracy of $80.6 \%$. Another dominant species, Liquidambar formosana, had relatively lower classification performance, because it was in a subdominant layer and many individuals were covered by Quercus acutissima. However, some species were misclassified by the pixel-based classification with low accuracy, due mainly to their low proportion. The season in which the images were acquired also had negative effects on tree species classification in some cases. In winter, the leaves of some deciduous tree species had fallen, and some trees were turning yellow or dying off, which would lead to a change in forest reflectance in the spectrum. Therefore, it is essential to classify forests by combining the data acquired in summer with those acquired in winter using other classification methods in future studies.

For the classification analysis of images with very high spatial resolution, object-based approaches are superior over pixel-based approaches when the pixel size is significantly smaller than the average size of the objects of interest [37,38]. Immitzer et al also found that by classifying objects instead of pixels, the user accuracies could increase significantly for most tree species in a forest study of a temperate zone [2], and the positive impact was higher for conifers than broadleaved trees. Additionally, there may be a "mixed pixels" issue in the pixel-based classification, i.e., the pixels within the tree crowns of large sizes might be classified into two or more different classes. The ITC-based classifier presented by Gougeon [28] can overcome this "mixed pixels" problem, which classifies the pixels within the single crown into the same species by comparing the signature of each tree crown with the ITC-based signatures of the various species using the Maximum-Likelihood algorithm. The results of the present study indicated that the crown-based classification improves the classified accuracy of both dominant species and smaller classes. This result is because the ITC-based classification cannot only avoid the pixels within tree crowns being classified into non-forested classes, such as building and road, but it can also mitigate the effect of the shadows between tree crowns on species classification. Therefore, the findings from this study lead to the recommendation of using the ITC-based instead of the pixel-based classification approach in classifying highly mixed forests.

Generally, the DN values of forestland in NIR bands were higher than those in other bands, such as Blue, Green and Red [39-41]. However, we determined that the band with the highest DN values was 
Green $(0.51-0.58 \mu \mathrm{m})$ for all of the species rather than the NIRs in this study, and the spectral values of forest areas in NIR bands were much lower than those of other published studies $[2,18,42]$. It is likely that the reflectances of forestland on NIRs were mainly affected by the structure of tree cells, and the image used in this study was taken in December 2011, when the low temperature in the study area inhibited the growth of trees and induced dormancy, thus resulting in changes in cell structure, such as a decrease in water content. The details of the influencing mechanisms require further study.

All of the extracted tree tops were annotated with species attributes from the thematic map established by the ITC-based supervised classifications, and the numbers of trees of different species were counted in this study. We studied how to interpret other parameters of forest resources, such as tree height, DBH and volume at the individual level, automatically by remote sensing. An available method to measure tree height using DSM (Digital Surface Model) minus DTM (Digital Terrain Model), which might be extracted from airborne LiDAR data, was reported by Katoh [43]. However, it is very difficult to interpret $\mathrm{DBH}$ information directly using satellite or airborne imagery. It has become possible to measure the DBHs of individual trees by regression models of DBH as the dependent variable and tree height as the independent variable and combining the location information of the extracted tree tops. Moreover, with the development of computer technology, some software, such as E3De v3.1, can automatically create three-dimensional models of individual trees using airborne LiDAR data with high point-densities, potentially enabling the interpretation of DBH. However, its usefulness needs to be verified in future studies.

\section{Conclusion}

The present study has measured the forest resources at Purple Mountain at the individual tree level using the WorldView-2 data by combining GPS, RS, and Geographic Information System (GIS) technologies. The tree tops were first interpreted by the ITC approach. Second, the study area was classified into two types of land cover with a total of 16 classes using the pixel-based classification. The results of our study suggested that the four new bands (Coastal, Yellow, Red-Edge and NIR2) of the WorldView-2 have a positive effect on the species classification. To overcome the "mixed pixels" problem of the pixel-based approach, a crown-based supervised classification was used for generating a thematic map of tree species. The findings from this study lead to the recommendation of using the crown-based instead of the pixel-based classification approach in classifying mixed forests. Finally, all tree tops were annotated with the species attributes from the thematic map, and a tree count of different species indicated that the forest of Purple Mountain is mainly dominated by Quercus acutissima, Liquidambar formosana and Pinus massoniana.

\section{Acknowledgments}

This study was supported by the National Basic Research Program of China (973 program, 2012CB416904), the Special Public-interests Forestry Project of the State Forestry Administration of China (No. 201104075) and the Natural Science Foundation of China (Grant No. 50978054, MCDA/GIS-based spatial decision making method for recreational forest in open urban space). We gratefully acknowledge a number of students of Nanjing Forestry University for their support in the field and the plot survey. We would like to thank the members of Forest Measurement and Planning 
Laboratory, Shinshu University, for their advice and assistance with this study. Besides, we wish to express heartfelt thanks to François A. Gougeon for providing the ITC Suite, a perfect procedure for forest inventories using remotely sensed images. We also sincerely thank Mohammad Abdullah AL FARUQ for his revisions and correction of the English in the paper. Finally, we wish to acknowledge the helpful comments of the five anonymous reviewers and editor.

\section{Conflicts of Interest}

The authors declare no conflict of interest.

\section{References}

1. Katoh, M.; Gougeon, F.A. Improving the precision of tree counting by combining tree detection with crown delineation and classification on homogeneity guided smoothed high resolution $(50 \mathrm{~cm})$ multispectral airborne digital data. Remote Sens. 2012, 4, 1411-1424.

2. Immitzer, M.; Atzberger, C.; Koukal, T. Tree species classification with random forest using very high spatial resolution 8-band WorldView-2 satellite data. Remote Sens. 2012, 4, 2661-2693.

3. State Forestry Administration of China. The Main Results of the 7th National Forest Resource Inventory (2004-2008) (in Chinese); 2010. Available online: http://www.forestry.gov.cn/portal/ main/s/65/content-326341.html (accessed on 6 February 2013).

4. Ke, Y.; Zhang, W.; Quackenbush, L.J. Active contour and hill climbing for tree crown detection and delineation. Photogramm. Eng. Remote Sens. 2010, 76, 1169-1181.

5. Wulder, M.; Niemann, K.O.; Goodenough, D.G. Local maximum filtering for the extraction of tree locations and basal area from high spatial resolution imagery. Remote Sens. Environ. 2000, 73, 103-114.

6. Clark, M.L.; Roberts, D.A.; Clark, D.B. Hyperspectral discrimination of tropical rain forest tree species at leaf to crown scales. Remote Sens. Environ. 2005, 96, 375-398.

7. Larsen, M. Single tree species classification with a hypothetical multi-spectral satellite. Remote Sens. Environ. 2007, 110, 523-532.

8. Nagendra, H. Using remote sensing to assess biodiversity. Int. J. Remote Sens. 2001, 22, 2377-2400.

9. Hill, D.A.; Leckie, D.G. Forest Regeneration: Individual Tree Crown Detection Techniques for Density and Stocking Assessments. In Proceedings of the International Forum on Automated Interpretation of High Spatial Resolution Digital Imagery for Forestry, Victoria, BC, Canada, 10-12 February 1998; pp. 169-177.

10. Jensen, J.R. Remote Sensing and GIS Integration. In Remote Sensing of the Environment: An Earth Resource Perspective, 2nd ed.; Prentice-Hall: Englewood Cliffs, NJ, USA, 2007; pp. 544-545.

11. Katoh, M. The Identification of Large Size Trees. In Forest Remote Sensing: Applications from Introduction (in Japanese), 3rd ed.; Japan Forestry Investigation Committee: Tokyo, Japan, 2010; pp. 308-309.

12. Leckie, D.G.; Gillis, M.D. A Crown-Following Approach to the Automatic Delineation of Individual Tree Crowns in High Spatial Resolution Aerial Images. In Proceedings of the International Forum on Airborne Multispectral Scanning for Forestry and Mapping, Chalk River, ON, Canada, 13-16 April 1993; pp. 86-93. 
13. Koukal, T.; Atzberger, C. Potential of multi-angular data derived from a digital aerial frame camera for forest classification. IEEE J. Sel. Top. Appl. Earth Obs. Remote Sens. 2012, 5, 30-43.

14. Gougeon, F.A.; Leckie, D.G. The individual tree crown approach applied to IKONOS images of a coniferous plantation area. Photogramm. Eng. Remote Sens. 2006, 72, 1287-1297.

15. Katoh, M. Comparison of high resolution IKONOS imageries to interpret individual trees (in Japanese with English abstract). J. Jpn. For. Soc. 2002, 84, 221-230.

16. Wang, L.; Gong, P.; Biging, G.S. Individual tree-crown delineation and treetop detection in high-spatial resolution aerial imagery. Photogramm. Eng. Remote Sens. 2004, 70, 351-357.

17. Erikson, M. Segmentation of individual tree crowns in color aerial photographs using region growing supported by fuzzy rules. Can. J. For. Res. 2003, 33, 1557-1563.

18. Katoh, M.; Gougeon, F.A.; Leckie, D.G. Application of high-resolution airborne data using individual tree crown in Japanese conifer plantations. J. For. Res. 2009, 14, 10-19.

19. Leckie, D.G.; Gougeon, F.A.; Walsworth, N.; Paradine, D. Stand delineation and composition estimation using semi-automated individual tree crown analysis. Remote Sens. Environ. 2003, 85, 355-369.

20. Leckie, D.G.; Gougeon, F.A.; Tinis, S.; Nelson, T.; Burnett, C.N.; Paradine, D. Automated tree recognition in old growth conifer stands with high resolution digital imagery. Remote Sens. Environ. 2005, 94, 311-326.

21. Pollock, R. A Model-Based Approach to Automatically Locating Individual Tree Crowns in High-Resolution Images of Forest Canopies. In Proceedings of the First International Airborne Remote Sensing Conference and Exhibition, Strasbourg, France, 12-15 September 1994; pp. 11-15.

22. Culvenor, D.S. Extracting Individual Tree Information. In Remote Sensing of Forest Environment: Concepts and Case Studies; Wulder, M., Franklin, S.E., Eds.; Kluwer Academic Publishers: Boston, MA, USA/Dordrecht, The Netherlands/London, UK, 2003; pp. 255-278.

23. Erikson, M.; Olofsson, K. Comparison of three individual tree crown detection methods. Mach. Vis. Appl. 2005, 16, 258-265.

24. Gougeon, F.A. A crown following approach to the automatic delineation of individual tree crowns in high spatial resolution aerial images. Can. J. Remote Sens. 1995, 21, 274-284.

25. Ke, Y.; Quackenbush, L.J. A comparison of three methods for automatic tree crown detection and delineation methods from high spatial resolution imagery. Int. J. Remote Sens. 2011, 32, 3625-3647.

26. Mutanga, O.; Adma, E.; Cho, M.A. High density biomass estimation for wetland vegetation using WorldView-2 imagery and random forest regression algorithm. Int. J. Appl. Earth Obs. Geoinf. 2012, 18, 399-406.

27. Sridharan, H. Multi-level Urban Forest Classification Using the WorldView-2 8-Band Hyperspectral Imagery. In 8 Bands Research Challenge; DigitalGlobe: Longmont, CO, USA, 2010.

28. Gougeon, F.A. The ITC Suite Manual: A Semi-Automatic Individual Tree Crown (ITC) Approach to Forest Inventories; Pacific Forestry Centre, Canadian Forest Service, Natural Resources Canada: Victoria, BC, Canada, 2010; pp. 1-92.

29. Deng, S.Q.; Yan, J.F.; Guan, Q.W. Spatial structure of scenic forest of Liquidamabar formosana in Nanjing Purple Mountain (in Chinese with English abstract). J. Nanjing For. Univ. (Natl. Sci. Ed.) 2010, 34, 117-122. 
30. Deng, S.; Yan, J.; Guan, Q.; Katoh, M. Short-term effects of thinning intensity on scenic beauty values of different stands. J. For. Res. 2013, 18, 209-219.

31. Hao, R.M.; Wei, H.T. Succession tendency of Zhongshan vegetation and discussion of possibility of reconstructing evergreen and deciduous broad-leaved mixed forest (in Chinese with English abstract). Acta Phytoecol. Sin. 1999, 23, 108-115.

32. Updike, T.; Comp, C. Radiometric Use of WorldView-2 Imagery; Technical Note; DigitalGlobe: Longmont, CO, USA, 2010.

33. Eckert, S. Improved forest biomass and carbon estimations using texture measures from WorldView-2 satellite data. Remote Sens. 2012, 4, 810-829.

34. Jiangsu Forestry Investigation and Planning Institute. Report on the Forest Resources of the Purple Mountain National Park (in Chinese); Purple Mountain National Park Administration: Nanjing, China, 2002; pp. 1-183.

35. Gougeon, F.A.; Leckie, D.G. Forest Information Extraction from High Spatial Resolution Images Using an Individual Tree Crown Approach; Canadian Forest Service: Victoria, BC, Canada, 2003; p. 27.

36. Landgrebe, D.; Biehl, L. An Introduction to MultiSpec (Version 5.01); Purdue University: West Lafayette, IN, USA, 2001; p. 27.

37. Whiteside, T.G.; Boggs, G.S.; Maier, S.W. Comparing object-based and pixel-based classifications for mapping savannas. Int. J. Appl. Earth Obs. Geoinf. 2011, 13, 884-893.

38. Yan, G.; Mas, J.F.; Maathuis, B.H.P.; Zhang, X.; van Dijk, P.M. Comparison of pixel-based and object-oriented image classification approaches - A case study in a coal fire area, Wuda, Inner Mongolia, China. Int. J. Remote Sens. 2006, 27, 4039-4055.

39. Haara, A.; Haarala, M. Tree species classification using semi-automatic delineation of trees on aerial images. Scand. J. For. Res. 2002, 17, 556-565.

40. Katoh, M. Classifying tree species in a northern mixed forest using high-resolution IKONOS data. J. For. Res. 2004, 9, 7-14.

41. Schlerf, M.; Atzberger, C. Vegetation structure retrieval in beech and spruce forests using spectrodirectional satellite data. IEEE J. Sel. Top. Appl. 2012, 5, 8-17.

42. Sridharan, H. Multi-Level Comparison of WorldView-2 8-Band and AISA Hyperspectral Imageries for Urban Forest Classification. In 8-Band Research Challenge; DigitalGlobe: Longmont, CO, USA, 2011.

43. Katoh, M. Tree Height Measurement Using LiDAR Data. In Forest Remote Sensing: Applications from Introduction (in Japanese); Japan Forestry Investigation Committee: Tokyo, Japan, 2004.

(C) 2013 by the authors; licensee MDPI, Basel, Switzerland. This article is an open access article distributed under the terms and conditions of the Creative Commons Attribution license (http://creativecommons.org/licenses/by/3.0/). 